\title{
Compactação e recalque superficial de um Latossolo Vermelho em condição de campo e laboratório ${ }^{1}$
}

\author{
Ródney F. Couto' ${ }^{2}$, Elton F. dos Reis ${ }^{2}$, Paulo M. F. Viana ${ }^{2}$, \\ Vandoir Holtz ${ }^{2}$, Lorena A. de Oliveira² \& Sueli M. de F. Alves ${ }^{2}$
}

\begin{abstract}
RESUMO
A aplicação de cargas dinâmicas no solo pelos rodados agrícolas, produz tensões na interface solo/pneu em superfície e profundidade. O objetivo deste trabalho foi avaliar a compactação e o recalque superficial de um Latossolo Vermelho quando submetido a diferentes níveis de tráfego em condições de campo e laboratório e propor uma metodologia para o ensaio de cargas dinâmicas oriundas de tráfegos de rodados pneumáticos, aplicável em laboratório. No campo foi utilizado um trator agrícola e no laboratório um simulador de tráfego. Nos dois experimentos foi adotado o delineamento em blocos ao acaso no esquema de parcelas subdivididas com quatro repetições. As parcelas foram constituídas de duas pressões de inflagem dos pneus: 96,5 e 137,9 kPa e as subparcelas, de cinco intensidades de tráfego: zero (testemunha), uma, duas, quatro e oito passadas do trator ou da roda do simulador, de acordo com o experimento. As variáveis mensuradas foram: densidade do solo, grau de compactação e recalque superficial. As duas primeiras variáveis foram analisadas na profundidade de $0-0,10 \mathrm{~m}$. O simulador de tráfego mostrou-se adequado para reproduzir as situações observadas no campo.
\end{abstract}

Palavras-chave: máquinas agrícolas, simulador de tráfego, grau de compactação

\section{Compaction and superficial settlement of an Oxisol under field and laboratory conditions}

\begin{abstract}
The application of dynamic loads in the soil, produces stress in wheel/soil interface in surface and depth. The aim of this study was to evaluate the compaction and superficial settlement of an Oxisol under different traffic levels under field and laboratory conditions; and to propose a methodology for dynamic load test, from traffic of the pneumatic wheel, applicable in the laboratory. In the field an agricultural tractor was used and in laboratory a traffic simulator. In the two experiments a randomized block design in split plots with four replications was adopted. The plots consisted of two tire inflation pressure: 96.5 and $137.9 \mathrm{kPa}$, and the subplots were five traffic intensities: zero (control), one, two, four and eight passes of the tractor or wheel simulator, according to the experiment. The variables measured were density of dry soil, degree of compactness and superficial settlement. The first two variables were analysed in the depth of 0-0.10 m. The traffic simulator was adequate to reproduce the situation observed in the field.
\end{abstract}

Key words: agricultural machineries, simulator of traffic, degree of compactness 


\section{INTRODUÇÃO}

As modificações nas propriedades físicas do solo, decorrentes do tráfego de máquinas nas operações agrícolas, têm sido amplamente estudadas (Schäfer-Landefeld et al., 2004; Chan et al., 2006; Schäffer et al., 2007) ressaltando-se os efeitos negativos da compactação do solo sobre a produtividade das culturas. Contudo, nas últimas décadas a mecanização das operações agrícolas tem-se intensificado resultando em aumento na carga aplicada pelas máquinas provocando, na maioria dos casos, a degradação física do solo em superfície e subsuperfície (Yavuzcan et al., 2005).

Os pneus usualmente utilizados nos tratores e colhedoras comercializadas no Brasil possuem a parte lateral do pneu rígida, chamados pneus de banda diagonal. Esta rigidez impede que o pneu se molde no solo de acordo com as irregularidades do terreno e, por conseguinte, sua área de contato fica reduzida aumentando a pressão na superfície do solo (Silva et al., 2000).

Pneus de mesma largura podem formar diferentes profundidades de recalque se inflados a pressões diferentes, ou seja, pressões de inflagem maiores implicam em maiores profundidades de recalque (McDonald et al., 1995).

Segundo Mialhe (1993) recalque é uma designação técnica com base no conceito de mecânica do solo e se trata do rebaixamento do leito de rolamento pelos rodados causando uma redução de volume e macroporos, com expulsão do ar e água neles existentes.

Conforme Chancellor (1977) a diminuição do volume de poros em virtude da compactação pelo tráfego de máquinas é aproximadamente igual ao volume do recalque produzido e os sulcos mais largos resultam em compactação mais superficialmente, se comparados aos mais estreitos.

Uma das principais propriedades físicas comumente utilizadas para caracterizar o estado de compactação é a densidade do solo (Ds) definida pela relação de massa de solo seca por unidade de volume. A Ds é capaz de detectar modificações de volume (Logsdon \& Karlen, 2004) fornecendo uma visão geral do estado do espaço poroso do solo.

Vários autores estudaram o aumento no valor da densidade do solo como resultado do processo de compactação. Freddi et al. (2007) avaliaram, em condições de campo, a compactação resultante da passagem de máquinas enquanto Foloni et al. (2003) estudaram o efeito de diferentes intensidades de compactação com o auxílio de equipamentos laboratoriais.

O processo de compactação promove alterações nas propriedades físicas do solo sendo que pesquisas têm sinalizado que o grau de compactação é sensível a essas mudanças. Suzuki et al. (2007) verificaram que o aumento do grau de compactação provocou redução linear da macroporosidade, da condutividade hidráulica saturada e aumento da resistência mecânica.
Silva et al. (2003) perceberam, fazendo uma análise dos objetivos e da forma como são realizados trabalhos correlatos, que a maioria deles é feita, geralmente, em uma condição estática e quase sempre voltados para a obtenção de um resultado qualitativo e comparativo cujas variáveis avaliadas são a densidade do solo e a porosidade. Os autores ressaltam, ainda, que três ponderações podem ser feitas: a primeira, de que as operações agrícolas ocorrem de forma dinâmica; a segunda, que a densidade do solo e a porosidade são fortemente dependentes do manejo e a terceira ressalta que quase sempre são desconsideradas informações, tais como o tipo de pneu, pressão de inflagem, pressão de contato, umidade do solo, profundidade de trabalho e especificações técnicas dos implementos utilizados.

Objetivou-se, neste trabalho, avaliar a compactação e o recalque superficial de um Latossolo Vermelho quando submetido a diferentes níveis de tráfego em condição de campo e laboratório e propor uma metodologia para ensaio de cargas dinâmicas, oriundas de tráfegos de rodados pneumáticos, aplicável em laboratório.

\section{Material e Métodos}

A área de estudo esteve sob o sistema plantio direto durante quatro anos e está sobre um Latossolo Vermelho textura argilosa (EMBRAPA, 2006) localizada na estação experimental da EMATER de Anápolis, GO; sua localização geográfica é definida pelas coordenadas $16^{\circ} 19^{\prime} \mathrm{S}$ e $48^{\circ} 18^{\prime} \mathrm{W}$, com altitude média de $980 \mathrm{~m}$.

Os resultados das análises de caracterização física e mecânica do solo são apresentados na Tabela 1 .

A área utilizada no experimento foi de 0,48 ha e as unidades experimentais, com dimensões de $7 \times 9 \mathrm{~m}$, foram demarcadas em nível com intervalos de 7 e $9 \mathrm{~m}$ para acesso e manobra do trator.

Foi adotado o delineamento em blocos ao acaso no esquema de parcelas subdivididas, composto por dez tratamentos com quatro repetições por tratamento, totalizando 40 unidades experimentais. As parcelas foram constituídas de duas pressões de inflagem dos pneus: 96,5 e 137,9 $\mathrm{kPa}$. As subparcelas foram as cinco intensidades de tráfego: zero (testemunha), uma, duas, quatro e oito passadas.

Durante os ensaios de campo utilizou-se, para simular o efeito do tráfego, um trator New Holland TT 4030, massa total de $3800 \mathrm{kgf}$ com lastros, com potência nominal do motor (na rotação nominal de $2500 \mathrm{rpm}$ ) de $55,1 \mathrm{~kW}(75 \mathrm{CV})$, pneu traseiro de construção diagonal com especificações técnicas 16,9x30R1, modelo Dyna torque II, cujas pressões de inflagem no momento dos ensaios foram de 96,5 e $137,9 \mathrm{kPa}$, de acordo com o tratamento.

Tabela 1. Valores de caracterização física e mecânica do Latossolo Vermelho sob plantio direto na profundidade de $0-0,10 \mathrm{~m}$

\begin{tabular}{|c|c|c|c|c|c|c|c|c|c|c|c|c|c|}
\hline \multicolumn{10}{|c|}{ Propriedades Físicas } & \multirow{2}{*}{\multicolumn{4}{|c|}{ Propriedades mecânicas }} \\
\hline \multicolumn{3}{|c|}{ Análise textural } & \multicolumn{4}{|c|}{ Índices físicos } & \multicolumn{3}{|c|}{ Limites de consistência } & & & & \\
\hline Areia & Silte & Argila & \multirow{3}{*}{$\begin{array}{l}W^{(1)} \\
(\%)\end{array}$} & \multirow{2}{*}{\multicolumn{2}{|c|}{$\frac{\rho_{d^{(1 / 7}}}{\left(\mathrm{t} \mathrm{m}^{-3}\right)}$}} & $\eta^{(4)}$ & $\mathrm{LL}^{(5)}$ & $L^{(6)}$ & $\mathbf{L C}^{(7)}$ & \multirow{3}{*}{$\begin{array}{c}\rho_{d m a ́ x}{ }^{(8)} \\
\left(\mathbf{t ~ m}^{-3}\right) \\
149\end{array}$} & $W_{0 t}^{(9)}$ & GC(10) & \multirow{3}{*}{$\begin{array}{r}\mathbf{R P}^{(11)} \\
(\mathrm{MPa}) \\
1,45\end{array}$} \\
\hline & $\left(\mathrm{g} \mathrm{kg}^{-1}\right.$ & & & & & \multicolumn{4}{|c|}{$(\%)$} & & \multicolumn{2}{|c|}{$(\%)$} & \\
\hline 450 & 110 & 440 & & 2,54 & 1,14 & 55,1 & 39,2 & 27,1 & 19,7 & & 27,7 & 76,6 & \\
\hline
\end{tabular}

(1)Umidade; (2)Massa específica dos sólidos/densidade de partículas; ${ }^{(3)}$ Massa específica do solo/densidade do solo; (4) Porosidade; (5) Limite de liquidez; (6)Limite de plasticidade; (7)Limite de contração; ${ }^{(8)}$ Massa especifica máxima/densidade máxima do solo; ${ }^{(9)}$ Umidade ótima de compactação; ${ }^{(10)}$ Grau de compactação/densidade relativa; e ${ }^{(11)}$ Resistência do solo à penetração 
Para o cálculo da pressão aplicada ao solo pelo trator, foi necessário determinar a área de contato do pneu com o solo e a distribuição da força peso do trator.

Com a finalidade de obter uma área de contato uniforme, foi polvilhado gesso em pó em toda a área, em torno do pneu traseiro direito do trator e em todos os espaços vazios entre as garras do pneu; em seguida, o trator foi içado com auxílio de um macaco hidráulico tomando-se cuidado para não danificar a depressão produzida pelo contato do rodado com solo. Após a elevação do trator a área de contato foi registrada por fotografia digital em alta resolução obtida em um plano paralelo ao solo utilizando-se uma câmera fotográfica SONY Cyber-Shot 14,1 Mega Pixels. O procedimento foi realizado para dois diferentes valores de pressões de inflagem dos pneus (96,5 e 137,9 kPa) e em vários locais da área experimental. As imagens resultantes foram analisadas no software AutoCad 2007, ocasião em que se efetuou a correção da escala e também a determinação das áreas de contato.

A determinação do valor da força peso que age na parte inferior do pneu traseiro do trator, foi realizada em uma balança mecânica industrial da marca Estrela, com capacidade para 19 $\mathrm{kN}$ e precisão de $2 \mathrm{~N}$. A pesagem foi realizada com o trator estando com o tanque com $50 \mathrm{~L}$ de combustível, operador de 80 $\mathrm{kg}$, com lastros metálicos na parte frontal e nos eixos dianteiro e traseiro e condição de lastragem líquida correspondente a $75 \%$ de água nos rodados traseiros. O peso obtido foi de $11,18 \mathrm{kN}$.

A magnitude da pressão média de contato aplicada pelo rodado ao solo foi calculada pela Eq. 1, proposta por Mialhe (1980):

$$
\mathrm{P}_{\mathrm{m}}=\frac{\mathrm{W}}{\mathrm{S}}
$$

em que:

$$
\begin{array}{ll}
\mathrm{P}_{\mathrm{m}} & \text { - pressão média aplicada ao solo pelo rodado, } \mathrm{Pa} \\
\mathrm{W} & \text { - carga suportada pelo rodado, } \mathrm{N} \\
\mathrm{S} & \text { - área de contato do rodado, } \mathrm{m}^{2}
\end{array}
$$

As pressões de contato foram de 252,5 e $142,2 \mathrm{kPa}$, respectivamente, para pressões de inflagem, de 96,5 e 137,9 kPa.

A influência do tráfego foi avaliada logo após as passadas do pneu traseiro, em movimentos de vai-e-vem, em uma pequena área de referência, de tal forma que o pneu dianteiro não se deslocasse sobre o rastro do pneu traseiro. Os tráfegos se constituíram de: zero (testemunha), uma, duas, quatro e oito passadas do trator, para cada pressão de inflagem do pneu. Foram realizadas coletas de amostras deformadas e indeformadas de solo, para determinação de propriedades físicas e mecânicas, em dois locais: a) na área referenciada e na profundidade de $0-0,10 \mathrm{~m}$ após o nível de tráfego adotado em cada tratamento e b) no espaço entre os rodados traseiros, profundidade de $0-0,20 \mathrm{~m}$, para serem utilizadas no experimento com simulador de tráfego.

Foram analisadas as seguintes variáveis: densidade do solo, grau de compactação e recalque superficial do solo. A densidade do solo foi determinada pelo método do anel volumétrico (EMBRAPA, 1997) e a amostragem realizada de forma aleatória no centro da linha de tráfego. Esta aleatoriedade tornou-se necessária tendo em vista que, muitas vezes, a distribuição das tensões não é uniforme de maneira que elas possam se concentrar em alguns pontos, como sob as marcas das garras do pneu ou no centro da área de contato do pneu com o solo. $\mathrm{O}$ grau de compactação (GC) foi obtido pela divisão da densidade do solo pela densidade máxima do solo obtida no ensaio de Proctor Normal e o recalque causado na superfície do solo pelo tráfego foi mensurado no sentido transversal à linha de tráfego utilizando-se um perfilômetro composto de 60 barras verticais distantes $10 \mathrm{~mm}$ umas das outras. Para todas as variáveis analisadas foram realizadas quatro repetições.

As variáveis obtidas foram submetidas à análise de variância pelo teste de F, a 0,05 de probabilidade e, quando houve diferença significativa entre os tratamentos, suas médias foram comparadas pelo teste de Tukey e também submetidas à análise de regressão.

Para avaliar o efeito dos diferentes níveis de tráfego e pressões de inflagem do pneu nas propriedades físicas e mecânicas do solo em condição laboratorial, foi utilizado um simulador linear de tráfego devidamente adaptado para a condição de solo agrícola.

Tal como na condição de campo, o experimento em laboratório foi conduzido no delineamento em blocos casualizados no esquema de parcelas subdivididas, também composto por dez tratamentos com quatro repetições por tratamento totalizando 40 unidades experimentais. As parcelas foram constituídas de duas pressões de inflagem do pneu: 96,5 e 137,9 $\mathrm{kPa}$ e as subparcelas por cinco intensidades de tráfego: zero (testemunha), uma, duas, quatro e oito passadas da roda do simulador de tráfego, de forma a induzir níveis de compactação com valores próximos aos aplicados pelo trator em campo.

O simulador possui um conjunto mecânico constituído, basicamente, por um braço articulado acoplado, em uma extremidade, a um redutor e na outra conectada a um eixo que contém uma roda. $\mathrm{O}$ acionamento se dá por motor elétrico monofásico de $3 / 4 \mathrm{CV}(0,55 \mathrm{~kW})$ e a transmissão de torque do motor para o redutor é feita por polia - correia.

O tráfego é simulado através da repetição da carga aplicada por uma roda submetida a esforço vertical e seu movimento longitudinal se dá sobre o corpo de prova. Na Figura 1A tem-

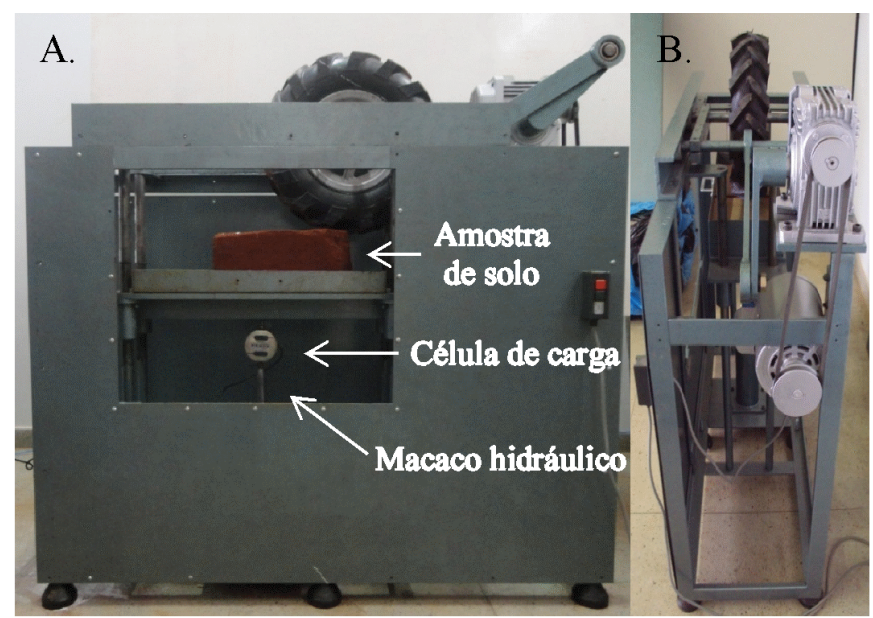

Figura 1. Vista frontal (A) e lateral direita (B) do simulador de tráfego 
se a vista frontal e na Figura 1B, a lateral direita do simulador de tráfego utilizado.

$\mathrm{Na}$ roda do simulador foi adaptado um pneu de motocultivador com as seguintes características: construção diagonal, medida 4,80-8, duas lonas, modelo PowerTrack fabricado pela Carslisle. Para comparação da compactação causada por pneus de diferentes medidas, trator e simulador de tráfego e inflados com a mesma pressão, utilizou-se o conceito de pressão média de contato também conhecido como tensão vertical, que representa a relação entre a carga (peso) sobre a área de contato do pneu com o solo. Desta forma, é possível aplicar e/ou reproduzir em uma superfície, qualquer valor de tensão alterando apenas o valor da carga vertical, desde que a área de contato seja constante.

O simulador de tráfego se diferencia de um trator agrícola basicamente na escala e na forma como a carga é aplicada ao solo. No caso do trator a carga é o próprio peso do eixo e no simulador devido às características construtivas, ou seja, ausência de um valor fixo de carga no eixo, o carregamento é aplicado por um macaco hidráulico que comprime a superfície das amostras de solo contra a banda de rodagem do pneu.

As áreas de contato foram obtidas seguindo-se a mesma metodologia utilizada no experimento em campo.

Para a aplicação do carregamento na superfície das amostras utilizou-se um macaco hidráulico com capacidade de duas toneladas força. A carga aplicada pelo macaco era monitorada por meio de uma célula de carga de $200 \mathrm{kgf}$ posicionada entre a placa de suporte das amostras e o macaco, conforme visto na Figura 1A.

O carregamento foi aplicado até que as amostras de solo fossem submetidas a valores de pressão de contato próximos aos determinados na condição de campo, ou seja, pressões de aproximadamente 252,5 e $142,2 \mathrm{kPa}$, de acordo com o tratamento.

As amostras indeformadas de solo (corpos de prova) utilizadas no simulador, foram extraídas na área do primeiro experimento, após o término de cada tratamento, no espaço entre os rodados traseiros e na profundidade de $0-0,20 \mathrm{~m}$. As amostras indeformadas foram coletadas até a profundidade de 0,20 m simplesmente para evitar que as mesmas sofressem um cisalhamento ao longo de sua extensão, o que inviabilizaria seu emprego no simulador de tráfego.

O procedimento de retirada das amostras indeformadas foi baseado na NBR 9604 (ABNT, 1986). As amostras possuíam dimensões de 0,20 x 0,24 x 0,40 m (altura, largura e comprimento). A sequência dos procedimentos pode ser descrita nos seguintes passos: (a) retirada da camada superior do solo com vegetação e escavação, com enxadão e picareta, de um cubo com dimensões um pouco superiores ao tamanho da amostra, até uma profundidade pouco maior que a altura do bloco; em seguida, foi feito o desbaste do bloco com uma espátula até serem atingidas as dimensões finais do bloco; (b) depois de talhado uma primeira camada de parafina (aquecida no campo em um fogareiro) foi despejada sobre a parte superior e nas laterais do bloco; (c) então, o bloco foi envolto com um tecido de malha fina e novamente parafinado até que ficasse completamente revestido; (d) com o facão e o martelo de geólogo escavou-se o bloco por baixo, até desprendê-lo; (e) cuidadosamente, o bloco foi virado; (f) e o excesso de solo retirado até ficar com as dimensões desejadas; (g) a parafina e o tecido de malha fina foram adicionados e daí se terminou de parafinar o bloco e (h) após a identificação, os blocos foram transportados para o laboratório e acondicionados em câmara úmida até a data de início dos testes.

Os tráfegos se constituíram de uma, duas, quatro e oito passadas do pneu do simulador, para cada pressão de inflagem do pneu $(96,5$ e $137,9 \mathrm{kPa})$.

Foram analisadas as seguintes variáveis: densidade do solo, grau de compactação e recalque superficial do solo. A densidade do solo foi determinada na profundidade de $0,10 \mathrm{~m}$ e de forma semelhante à descrita no primeiro experimento mas se utilizando um anel cilíndrico de menor diâmetro $(0,05 \mathrm{~m})$. $\mathrm{O}$ volume de solo não foi obtido por queda livre do soquete de cravação mas se talhando o maciço de solo até que ele adquirisse as dimensões do anel cilíndrico. O grau de compactação também foi determinado a $0,10 \mathrm{~m}$ de profundidade, como descrito no primeiro experimento. $\mathrm{O}$ recalque superficial foi mensurado utilizando-se o método fotográfico descrito em detalhes por Bueno (1987). Para todas as variáveis analisadas foram realizadas quatro repetições.

As variáveis obtidas foram submetidas à análise de variância pelo teste de $\mathrm{F}$, a $5 \%$ de probabilidade e, quando houve diferença significativa entre os tratamentos, suas médias foram comparadas pelo teste de Tukey e também submetidas à análise de regressão.

A validação do simulador de tráfego foi realizada por uma análise de agrupamento de experimentos (análise conjunta) a fim de se verificar a similaridade ou diferenças entre os experimentos com a aplicação do teste $\mathrm{F}$ a $5 \%$ de probabilidade. Em todos os procedimentos estatísticos descritos neste trabalho foi utilizado o programa SISVAR 5.3 (Ferreira, 2007).

\section{Resultados e Discussões}

O resultado da análise conjunta (agrupamento) de experimentos demonstrou que todas as variáveis sofreram influência apenas do tráfego $(\mathrm{P}<0,05)$ e que o comportamento dos níveis de tráfego é o mesmo nos dois experimentos.

Para as duas condições experimentais a pressão média aplicada ao solo pelo tráfego de quatro passadas aumentou a densidade do solo em relação à testemunha ausência de tráfego (Figura 2 e Tabela 2).

Esses resultados corroboram com os encontrados por Silva et al. (2011) que, avaliando a intensidade do tráfego de duas, quatro e oito vezes de um Forwarder sobre a compactação de um Latossolo Vermelho-Amarelo nas profundidades de (0-0,03 $\mathrm{m})$ e $(0,10-0,13 \mathrm{~m})$ concluíram que todas as intensidades de tráfego causaram compactação no solo nas duas profundidades estudadas, sendo quatro passadas as que ocasionaram maior compactação do solo. O número de passadas igual a oito causou menor compactação que o número de passadas igual a quatro na profundidade de $0-0,03 \mathrm{~cm}$.

Embora não avaliada neste estudo, a elasticidade do solo pode ser o motivo da redução da densidade do solo após o tráfego de quatro passadas. Na compressão de solo não-saturado uma parte do ar fica aprisionada no seu interior, com formação 


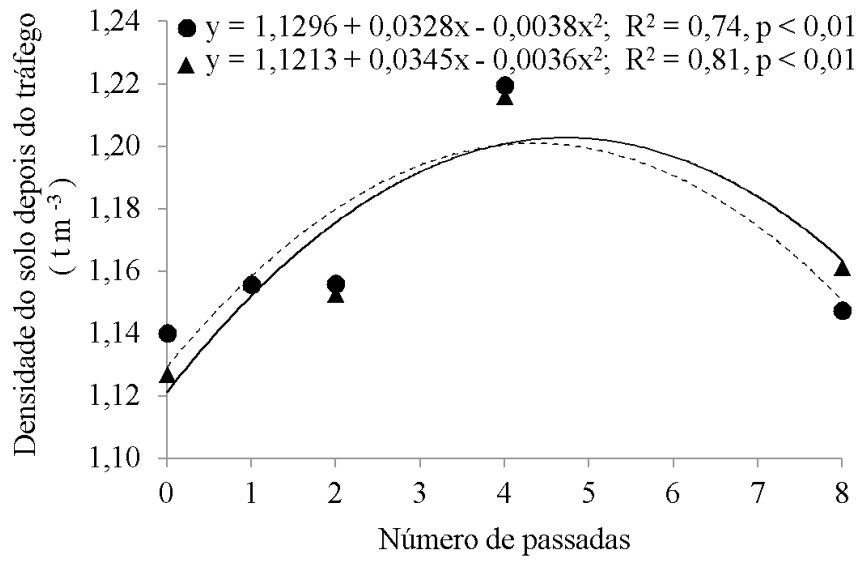

- Trator Agrícola $\quad$ A Simulador de Tráfego

Figura 2. Densidade do solo após o tráfego em função do número de passadas do pneu nas duas condições experimentais

Tabela 2. Valores médios de densidade do solo $(t$ $\mathrm{m}^{-3}$ ) após aplicação dos níveis de tráfego para cada condição experimental

\begin{tabular}{ccc}
\hline $\begin{array}{c}\text { Intensidade de } \\
\text { tráfego } \\
\text { (Passadas) }\end{array}$ & \multicolumn{2}{c}{ Condição experimental } \\
\cline { 2 - 3 } 0 & $\begin{array}{c}\text { Campo } \\
\text { (Trator agrícola) }\end{array}$ & $\begin{array}{c}\text { Laboratório } \\
\text { (Simulador de tráfego) }\end{array}$ \\
1 & $1,14 \mathrm{aA}$ & $1,13 \mathrm{aA}$ \\
2 & $1,16 \mathrm{abA}$ & $1,16 \mathrm{aA}$ \\
4 & $1,16 \mathrm{abA}$ & $1,15 \mathrm{aA}$ \\
8 & $1,22 \mathrm{bA}$ & $1,22 \mathrm{bA}$ \\
& $1,15 \mathrm{aA}$ & $1,16 \mathrm{abA}$ \\
\hline
\end{tabular}

Médias seguidas de mesma letra minúscula na coluna não diferem entre si pelo teste de Tukey $(P>0,05)$. Médias seguidas de mesma letra maiúscula na linha não diferem entre si pelo teste de $\mathrm{F}$ do agrupamento de experimentos $(\mathrm{P}>0,05)$

de bolhas de ar comprimido que, após o descarregamento, se expandem, deslocando o solo (Perdok et al., 2002). Assim, o solo retorna, em parte, ao seu volume natural reduzindo o valor da densidade.

Os valores do grau de compactação após aplicação das energias de compactação provenientes dos diferentes níveis de tráfego, para as duas condições experimentais, apresentaram comportamento quadrático evidenciado nas análises de regressão. O maior grau de compactação foi obtido para o tráfego de quatro passadas (Figura 3). No experimento de campo o comportamento foi semelhante porém com equação $\mathrm{y}=75,651+2,0082 \mathrm{x}-0,2183 \mathrm{x}^{2}$, coeficiente de determinação $\mathrm{R}^{2}=0,59$ e $\mathrm{p}<0,05$.

Como o grau de compactação é uma razão entre duas densidades, ou seja, a densidade do solo pela densidade de referência obtida pelo ensaio de Proctor Normal e os valores da densidade de referência foram semelhantes em toda a área do experimento, o comportamento desta variável foi condicionado quase que exclusivamente pela densidade do solo (Tabela 3 ).

Ainda na Tabela 3 é possível observar que o grau de compactação oriundo do tráfego de quatro passadas, nos dois experimentos, diferiu dos tráfegos de zero e duas passadas, mas não de oito. Esses resultados corroboram com os de Jorajuria \& Draghi (1997) e Hamza \& Anderson (2005) os quais, analisando o grau de compactação na superfície do solo, obtiveram

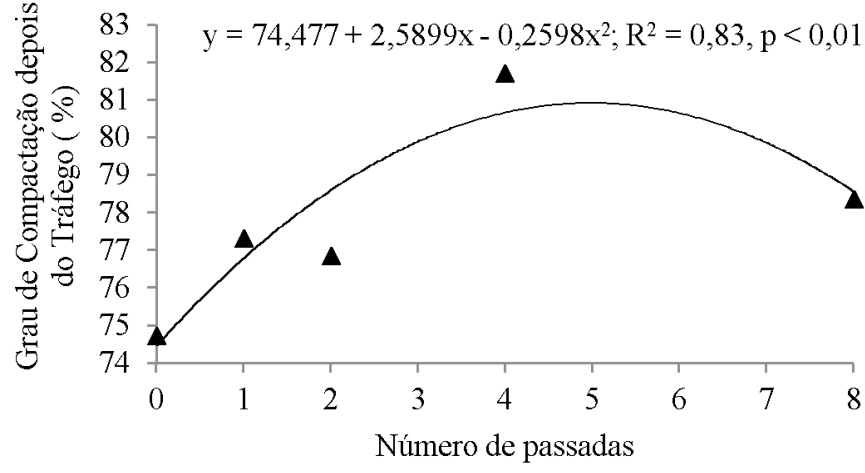

Figura 3. Grau de compactação do solo após o tráfego em função do número de passadas do pneu no experimento realizado em laboratório com o emprego do simulador de tráfego

Tabela 3. Valores médios do grau de compactação do solo (\%) após aplicação dos níveis de tráfego para cada condição experimental

\begin{tabular}{ccc}
\hline $\begin{array}{c}\text { Intensidade de } \\
\text { tráfego }\end{array}$ & \multicolumn{2}{c}{ Condição experimental } \\
\cline { 2 - 3 } (Passadas) & $\begin{array}{c}\text { Campo } \\
\text { (Trator agrícola) }\end{array}$ & $\begin{array}{c}\text { Laboratório } \\
\text { (Simulador de tráfego) }\end{array}$ \\
0 & $76,70 \mathrm{aA}$ & $74,76 \mathrm{aA}$ \\
1 & $76,94 \mathrm{aA}$ & $77,36 \mathrm{abA}$ \\
2 & $76,89 \mathrm{aA}$ & $76,89 \mathrm{aA}$ \\
4 & $81,84 \mathrm{bA}$ & $81,74 \mathrm{bA}$ \\
8 & $77,46 \mathrm{abA}$ & $78,40 \mathrm{abA}$ \\
\hline
\end{tabular}

Médias seguidas de mesma letra minúscula na coluna não diferem entre si pelo teste de Tukey $(P>0,10)$. Médias seguidas de mesma letra maiúscula na linha não diferem entre si pelo teste de $F$ do agrupamento de experimentos $(P>0,05)$

maiores incrementos logo após as primeiras passadas; nas duas condições experimentais o grau de compactação oriundo de quatro passadas foi superior a $80 \%$.

Beutler et al. (2008) observaram, quantificando a produtividade das culturas da soja e do milho, em Latassolo Vermelho de textura média, que um grau de compactação de até 79 e $81 \%$, respectivamente para a soja e o milho, favoreceu a obtenção de produtividades máximas, conforme também verificado na literatura (Al-Adawi \& Reeder, 1996; Beutler et al., 2004; 2005). A partir desses níveis de compactação ocorreu decréscimo da produtividade relacionado a dois fatores físicos do solo: ao impedimento mecânico e à falta de oxigênio para o crescimento das raízes, conforme também constatado por Silva et al. (2004).

Silva et al. (1997) pesquisaram a influência da textura do solo, matéria orgânica e tipo de manejo na densidade do solo e na densidade relativa (grau de compactação) e verificaram que a densidade do solo foi fortemente influenciada pelos fatores mencionados enquanto o uso da densidade relativa praticamente eliminou os efeitos da textura e do teor de matéria orgânica realçando o efeito do tipo de manejo e intensidade do tráfego de máquinas sobre o solo.

As análises de regressão para o recalque do solo, nas duas condições experimentais, em função da intensidade de tráfego apresentaram ajuste linear. Com o aumento do tráfego houve tendência de aumento no recalque do solo (Figura 4). No experimento de campo o comportamento foi semelhante porém com equação $\mathrm{y}=10,643+0,6784 \mathrm{x}$, coeficiente determinação $\mathrm{R}^{2}=0,52$ e $\mathrm{p}<0,01$. 


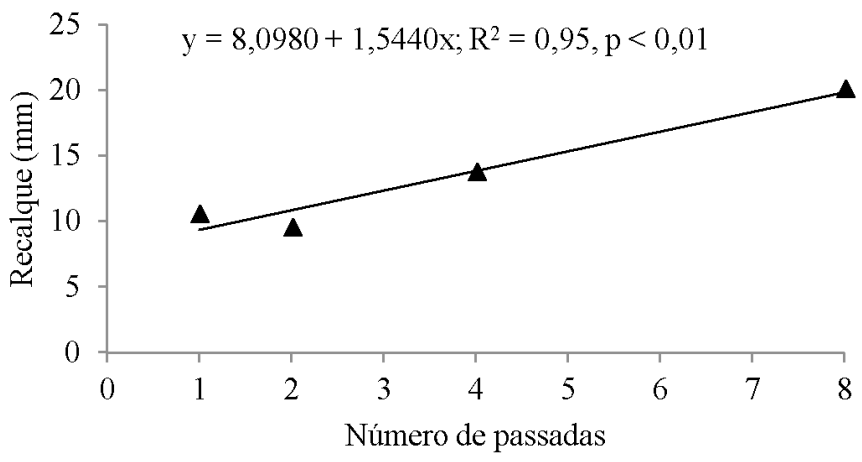

Figura 4. Recalque do solo em função do número de passadas do pneu no experimento realizado em laboratório com o emprego do simulador de tráfego

Os recalques do solo oriundos do tráfego do simulador tiveram de ser corrigidos devido ao efeito escala. $\mathrm{O}$ fator de correção ou fator de escala levou em consideração o somatório das áreas de contato de cada pneu e foi obtido dividindo-se a área de contato total do pneu do simulador pela área de contato total do pneu do trator, obtendo-se uma escala de 1:20, ou seja, a área total de contato do pneu do simulador é vinte vezes menor que a do trator.

O teste de comparação de médias (Tabela 4) demonstrou que os maiores recalques foram obtidos para oito passadas, nos dois experimentos, e foram estatisticamente diferentes dos recalques obtidos para uma única passada discordando, portanto, dos resultados de Fenner (1999) que, fazendo um estudo de tráfego controlado em solos da Amazônia, verificou que as maiores deformações ocorrem logo após a primeira passada da máquina, sendo os efeitos das passagens subsequentes mais reduzidos.

Tabela 4. Média dos recalques do solo $(\mathrm{mm})$ para os experimentos com trator agrícola e simulador de tráfego

\begin{tabular}{ccc}
\hline $\begin{array}{c}\text { Intensidade } \\
\text { de tráfego } \\
\text { (Passadas) }\end{array}$ & \multicolumn{2}{c}{ Condição experimental } \\
\cline { 2 - 3 } 1 & $\begin{array}{c}\text { Trator } \\
\text { agrícola }\end{array}$ & $\begin{array}{c}\text { Simulador } \\
\text { escala corrigida }\end{array}$ \\
2 & $9,11 \mathrm{aA}$ & $10,60 \mathrm{aA}$ \\
4 & $14,66 \mathrm{abA}$ & $9,58 \mathrm{aA}$ \\
8 & $13,23 \mathrm{abA}$ & $13,80 \mathrm{abA}$ \\
\hline
\end{tabular}

Médias seguidas de mesma letra minúscula na coluna não diferem entre si pelo teste de Tukey $(P>0,05)$. Médias seguidas de mesma letra maiúscula na linha não diferem entre si pelo teste de $F$ do agrupamento de experimentos $(P>0,05)$

Esta diferença é explicada pelo fato de que, para cada tráfego no experimento de Fenner (1999) correspondia a duas passadas do pneu sobre a mesma porção de solo visto que o pneu traseiro transitava sobre a trilha de roda formada pelo pneu dianteiro, ao contrário dos experimentos com trator agrícola e simulador de tráfego em que cada nível de tráfego era idêntico ao número de passadas do pneu.

\section{CONCLUSÕES}

1. As pressões de inflagem do pneu e a interação entre pressões e níveis de tráfego adotados neste estudo não afetaram, de forma significativa, na compactação do solo nem no recalque superficial, para as duas condições experimentais.
2. A intensidade de tráfego foi o único fator que influenciou nas variáveis analisadas.

3. O tráfego de quatro passadas foi o que proporcionou maiores valores de densidade do solo e grau de compactação.

4. O maior recalque superficial do solo ocorreu para o tráfego de oito passadas.

5. A metodologia proposta e validada mostra-se interessante para emprego em laboratórios de solo visando atender interesses de produtores rurais e agroindústrias, principalmente nas atividades agrícolas que demandam altas intensidades de tráfego.

\section{Agradecimentos}

Os autores agradecem à Fundação de Amparo à Pesquisa do estado de Goiás (FAPEG), pelo apoio financeiro a esta pesquisa; à LTEC - Laboratório Técnico e Engenharia, pelo auxílio à pesquisa e à CAPES, pela concessão da bolsa de estudo.

\section{Literatura Citada}

ABNT - Associação Brasileira de Normas Técnicas. NBR 9604: Abertura de poço e trincheira de inspeção em solo com retirada de amostras deformadas e indeformadas. Rio de Janeiro: ABNT, 1986. 9p.

Al-Adawi, S. S.; Reeder, R. C. Compaction and subsoiling effects on corn and soybean yields and soil physical properties. Transactions of the ASAE, v.39, p.1641-49, 1996.

Beutler, A. N.; Centurion, J. F.; Roque, C. G.; Ferraz, M. V. Densidade relativa ótima de Latossolos Vermelhos para a produção de soja. Revista Brasileira de Ciência do Solo, v.29, p.843-849, 2005.

Beutler, A. N.; Centurion, J. F.; Silva, A. P. Intervalo hídrico ótimo e a produção de soja e arroz em dois Latossolos. Irriga, v.9, p.181-92, 2004.

Beutler, A. N.; Freddi, O. S.; Leone, C. L.; Centurio, J. F. Densidade do solo relativa e parâmetro "S" como indicadores da qualidade física para culturas anuais. Revista de Biologia e Ciências da Terra, v.8, p.27-36, 2008.

Bueno, B. S. The behavior of thin walled pipes in trenches. Leeds: Leeds University, 1987. 325p. Ph.D.

Chan, K. Y.; Oates, A.; Swan, A. D.; Hayes, R. C.; Dear, B. S.; Peoples, M. B. Agronomic consequences of tractor wheel compaction on a clay soil. Soil and Tillage Research, v.89, p.13-21, 2006.

Chancellor, W. J. Compaction of soil by agricultural equipment. Davis: University of California, 1977. 53p.

EMBRAPA - Empresa Brasileira de Pesquisa Agropecuária. Centro Nacional de Pesquisa de Solos. Manual de métodos de análise de solo. Rio de Janeiro: Embrapa Solos. 1997. 212p.

EMBRAPA - Empresa Brasileira de Pesquisa Agropecuária. Centro Nacional de Pesquisa de Solos. Sistema Brasileiro de Classificação de Solos. Rio de Janeiro: Embrapa Solos, 2006. 306p.

Fenner, P. T. Relações entre tráfego, solo e desenvolvimento florestal na colheita da madeira. Botucatu: Universidade Estadual de São Paulo, 1999. 135p. Tese Livre Docência 
Ferreira, D. F. Sisvar - Sistema de análise de variância. Versão 5.3. Lavras: UFLA, 2007.

Foloni, J. S. S.; Calonego, J. C.; Lima, S. L. Efeito da compactação do solo no desenvolvimento aéreo e radicular de cultivares de milho. Pesquisa Agropecuária Brasileira, v.38, p.947-953, 2003.

Freddi, O. S.; Centuron, J. F.; Beutler, A. N.; Aratani, R. G.; Leonel, C. L.; Silva, A. P. Compactação do solo e intervalo hídrico ótimo no crescimento e na produtividade da cultura do milho. Bragantia, v.66, p.477-486, 2007.

Hamza, M. A.; Anderson, W. K. Soil compaction in cropping systems: A review of the nature, causes and possible solutions. Soil and Tillage Research, v.82, p.121-145, 2005.

Jorajuría, D.; Draghi, L. The distribution of soil compaction with depth and the response of a perennial forage crop. Journal of Agricultural Engineering Research, v.66, p.261$265,1997$.

Logsdon, S. D.; Karlen, D. L. Bulk density as a soil quality indicator during conversion to no-tillage. Soil and Tillage Research, v.78, p.143-149, 2004.

McDonald, T. P.; Stokes, B. J.; Aust, W. M. Soil physical property changes after skidder traffic with varying widths. Journal of Forest Engineering, v.6, p.41-50, 1995.

Mialhe, L. G. Máquinas motoras na agricultura. São Paulo: USP, v.2, 1980. 365p.

Mialhe, L. G. O estado da arte e perspectivas da utilização de rodados pneumáticos de baixa pressão na área agrícola. In: Encontro sobre Pneus de Alta Flutuação e Baixa Pressão nas Áreas Agrícola e Florestal, 1993, Piracicaba. Anais... Piracicaba: ESALQ, 1993. p.1-17.

Perdok, U. D.; Kroesbergen, B.; Hoogmoed, W. B. Possibilities for modeling the effect of compression on mechanical and physical properties of various Dutch soil types. Soil and Tillage Research, v.65, p.61-75, 2002.
Schäfer-Landefeld, L.; Brandhuber, R.; Fenner, S.; Koch, H-J.; Stockfisch, N. Effects of agricultural machinery with high axle load on soil properties of normally managed fields. Soil and Tillage Research, v.75, p.75-86, 2004.

Schäffer, B.; Attinger, W.; Schulin, R. Compaction of restored soil by heavy agricultural machinery - Soil physical and mechanical aspects. Soil and Tillage Research, v.93, p.2843, 2007.

Silva, A. P.; Imnhoff, S.; Kay, B. Plant response to mechanical resistance and air- filled porosity of soils under conventional and no-tillage system. Scientia Agricola, v.61, p.451-456, 2004.

Silva, A. P.; Kay, B. D.; Perfect, E. Management versus inherent soil properties effects on bulk density and relative compaction. Soil and Tillage Research, v.44, p.81-93, 1997.

Silva, A. R.; Dias Júnior, M. S.; Palha Leite, F. P. Avaliação da intensidade de tráfego e carga de um Forwarder sobre a compactação de um Latossolo Vermelho-Amarelo. Revista Árvore, v.35, p.547-554, 2011.

Silva, R. B.; Dias Júnior, M. S.; Silva, F. A. M.; Fole, S. M. $\mathrm{O}$ tráfego de máquinas agrícolas e as propriedades físicas, hídricas e mecânicas de um Latossolo dos Cerrados. Revista Brasileira de Ciência do Solo, v.27, p.973-983, 2003.

Silva, V. R.; Reinert, D. J.; Reichert, J. M. Resistência mecânica do solo à penetração influenciada pelo tráfego de uma colhedora em dois sistemas de manejo do solo. Ciência Rural, v.30, p.795-801, 2000.

Suzuki, L. E. A. S.; Reichert, J. M.; Reinert, D. J.; Lima, C. L. R. Grau de compactação, propriedades físicas e rendimento de culturas em Latossolo e Argissolo. Pesquisa Agropecuária Brasileira, v.42, p.1159-1167, 2007.

Yavuzcan, H. G.; Matthies, D.; Auernhammer, H. Vulnerability of Bavarian silty loam soil to compaction under heavy whell traffic: impacts of tillage method and soil water content. Soil and Tillage Research, v.84, p.200-215, 2005. 